\title{
Comparative account of allelopathic potential of essential oil of Tagetes minuta L. and its major component cis- $\beta$-Ocimene
}

Komal Arora $^{1 *}$, Daizy Batish ${ }^{2}$, Harminder Pal Singh ${ }^{3}$ and Ravinder Kumar Kohli ${ }^{4}$

${ }^{1}$ Department of Botany, DAV College, Jalandhar, Punjab - 144008, India.

2Department of Botany, Panjab University, Chandigarh -160014, India.

3Department of Environment Studies, Panjab University, Chandigarh - 160014, India.

${ }^{4}$ Central University of Punjab, Bathinda, Punjab - 151001, India.

Received: August 17, 2016; Revised: August 17, 2016; Accepted: September 17, 2016

\begin{abstract}
The study aims to explore the chemical composition of volatile essential oil of Tagetes minuta and comparison of its allelopathic potential with cis- $\beta$-ocimene, a major component of oil. T. minuta L. is an exotic aromatic plant found growing in northern plains and western Himalayas in India. The water distilled essential oil from aerial parts of T. minuta (at flowering stage) was analyzed by GC-MS. The analysis revealed 27 compounds representing $95.73 \%$ of the oil. cis- $\beta$-Ocimene $(44.56 \%)$, dihydrotagetone $(28.52 \%)$, limonene $(3.99 \%)$ and tagetone $(7.42 \%)$ were its major compounds. A comparison of allelopathic effect of $c i s-\beta$-ocimene was made with T. minuta oil using Cassia occidentalis L., a common wasteland weed, as test plant. Laboratory study included growth studies in the form of germination, seedling length and dry weight of test plant under both treatments i.e. T. minuta oil and cis$\beta$-ocimene. The inhibitory effect of ocimene was more significant as compared to oil. However, highest concentration $(20 \mu \mathrm{g} / \mathrm{cc})$ of both treatments was found to be inhibitory with respect to all parameters.
\end{abstract}

Key words: Allelopathy; Cassia occidentalis; cis- $\beta$-ocimene; essential oil; GC-MS; Tagetes minuta.

\section{Introduction}

Tagetes (Family Asteraceae) species are cultivated world over for its ornamental value and essential oil. Among these, Tagetes minuta L. is an important species to yield highest oil among all cultivated Tagetes species (Singh et al., 2003). It is traditionally used in folklore medicine for treating different ailments and is credited with several pharmacological and biological activities (Syamasundar \& Rao 2013). It originated in South America but has spread throughout the world as a weed (Singh et al., 2003). In India, it is found growing along road-sides and wastelands in the regions of Northern plains and Western Himalayas including Solan, Himachal Pradesh, India and adjoining areas. Numerous reports have appeared on chemical composition of its essential oil (Chamorro et al., 2008; Breme et al., 2009; Meshkatalsadat et al., 2010; Shahzadi et al., 2010; Shirazi et al., 2014) but no information has been reported on the comparative allelopathic impact of T. minuta oil in relation to its major component cis$\beta$-ocimene. Thus present study was designed to explore the allelopathic potential of oil in comparison to cis- $\beta$-ocimene on growth of Cassia occidentalis (Family Fabaceae), a wasteland weed.

\section{Materials and Methods}

\section{Plant collection and oil extraction}

The plant was collected at flowering stage from Solan and adjoining places of Himachal Pradesh, India $\left(30^{\circ} 55^{\prime} 0^{\prime \prime}\right.$ North, $77^{\circ} 7^{\prime} 0^{\prime \prime}$ East). Aerial parts of plant $(1 \mathrm{Kg})$ were subjected to hydro-distillation for $2 \mathrm{~h}$ using a Clevenger-type apparatus. Seeds of $C$. occidentalis were collected from wildly growing

\section{${ }^{*}$ Corresponding Author:}

\section{Dr. Komal Arora,}

Head, Department of Botany,

DAV College, Jalandhar,

Punjab, India.

E-mail: komal.swami@yahoo.com strands in and around Panjab University, Chandigarh, India (3045'34" North 76²4'59" East).

\begin{abstract}
Analysis of the essential oil and identification of its components

GC-MS analysis was carried out with QP2010 Mass spectrometer equipped with fused silica BP- 21 Column $(30 \mathrm{~m} \times 0.25 \mathrm{~mm}, 0.25 \mu \mathrm{m}$ film thickness). The carrier gas used was helium. Injector temperature was set at $250^{\circ} \mathrm{C}$. Oven temperature was programmed from $70^{\circ} \mathrm{C}$, held isothermal for 4 min and then increased @ $4^{\circ} \mathrm{C} / \mathrm{min}$ upto $220^{\circ} \mathrm{C}$ and held isothermal for $5 \mathrm{~min}$. For mass spectrometer, ion source and interface temperatures were 200 and $250^{\circ} \mathrm{C}$, respectively. Solvent cut time was $3.50 \mathrm{~min}$ and start and end $\mathrm{m} / \mathrm{z}$ were 50 and 800 till the detection of ions completed at $46 \mathrm{~min}$ (end time).
\end{abstract}

Compound identification was based on computer matching of mass spectra using library search system of HP-5872 (Hewlett-Packard) consulting databases vi\%: Wiley 275 and NBS 75K libraries (Mc Lafferty, 1989), NIST 98 (Stein, 1990) and compilation by Adams (1995).

\section{Growth study}

To test the inhibitory effect of T. minuta oil and cis$\beta$-ocimene on $C$. occidentalis, 20 seeds of weed (after imbibition) were placed on Whatman no. 1 filter paper moistened with $8 \mathrm{ml}$ of distilled water. $T$. minuta oil and cis- $\beta$-ocimene were applied in various amounts $(0.625,1.25,2.5,5,10 \& 20 \mu \mathrm{g} / \mathrm{cc}$ per Petri 
dish) on lid of Petri dishes and sealed immediately with parafilm. A similar treatment with water served as control. For each treatment five replicates were placed in a completely randomized design in growth chamber, maintained at 16/8-hour light/dark period and temperature $25 \pm 2^{\circ} \mathrm{C}$. Relative humidity was $80 \%$ and irradiance was $150 \mu$ mole $\mathrm{m}^{-2} \mathrm{sec}^{-1}$. After seven days, germinated seeds were counted and seedling lengths and dry weights were measured. cis- $\beta$-Ocimene of analytical grade was purchased from Sigma-Aldrich (St. Louis, MO, USA).

\section{Statistical Analysis}

For each treatment (including control), five replicates were kept in a completely randomized manner. Data were subjected to one-way analysis of variance followed by separation of treatment means from the control at $\mathrm{p}<0.01$ and 0.05 applying posthoc Dunnett's Test using SPSS PC software.

\section{Results and Discussion}

GC-MS analysis of hydro-distilled aerial parts of $T$. minuta revealed 27 compounds accounting 95.73\% of oil (Table 1). Major constituents of oil were identified to be cis- $\beta$-ocimene (44.56\%), dihydrotagetone $(28.52 \%)$, limonene $(3.99 \%)$ and tagetone $(7.42 \%)$ (Table 1$)$. Considerable variation in the composition of volatile oil within this species has been reported in many previous reports (Mohamed et al., 2002; Senatore et al., 2004; Moghaddam et al., 2007) which have been attributed to different climatic \& geographical conditions, stage of harvesting and method of distillation of oil.

Table 1: Chemical composition of the essential oil of T. minuta

\begin{tabular}{cccccccc}
\hline No & Compound & RRI & $\mathbf{\%}$ & No & Compound & RRI & \% \\
\hline 1 & $\beta$-Myrcene & 1162 & 0.09 & 15 & Linalool & 1548 & 0.08 \\
2 & $\alpha$-Phellandrene & 1165 & 0.06 & 16 & trans-Caryophyllene & 1582 & 0.81 \\
3 & dl-Limonene & 1199 & 3.99 & 17 & $\alpha$-Humulene & 1654 & 0.36 \\
4 & $\beta$-Phellandrene & 1205 & 0.05 & 18 & cis-Ocimenone & 1685 & 1.36 \\
5 & cis- $\beta$-Ocimene & 1237 & 44.56 & 19 & Germacrene- D & 1692 & 0.42 \\
6 & trans- $\beta$-Ocimene & 1253 & 0.45 & 20 & trans-Ocimenone & 1703 & 1.63 \\
7 & n-Octanal & 1289 & 0.10 & 21 & Bicyclo-germacrene & 1717 & 1.07 \\
8 & Dihydrotagetone & 1309 & 28.52 & 22 & Carveol & 1822 & 0.05 \\
9 & a-Pinene oxide & 1358 & 0.12 & 23 & Piperitenone & 1905 & 0.17 \\
10 & allo-Ocimene & 1373 & 1.68 & 24 & Spathulenol & 2109 & 0.13 \\
11 & Artemisia ketone & 1448 & 0.08 & 25 & Cedrol & 2321 & 0.16 \\
12 & Myroxide-Z & 1465 & 0.12 & 26 & n-Tetracosane & 2393 & 1.09 \\
13 & cis-Tagetone & 1506 & 3.85 & 27 & n-Hexacosane & 2661 & 1.18 \\
14 & trans-Tagetone & 1508 & 3.55 & & & & \\
& & Total Identified Compounds & 95.73 \% & & \\
\hline
\end{tabular}

Note: RRI, relative retention indices calculated against $n$-alkanes, $\%$ calculated from FID data

Table 2: Effect of T. minuta oil and cis- $\beta$-ocimene on growth of $C$. occidentalis

\begin{tabular}{|c|c|c|c|c|c|c|c|c|}
\hline \multirow{2}{*}{ Parameter } & \multirow{2}{*}{ Treatment } & \multicolumn{7}{|c|}{ Concentrations ( $\mu \mathrm{g} / \mathrm{cc})$} \\
\hline & & 0 & 0.625 & 1.25 & 2.5 & 5 & 10 & 20 \\
\hline \multirow{2}{*}{ Percent Germination } & $\mathrm{Tm}$ & $98.3 \pm 2.9$ & $95.0 \pm 5.0^{\mathrm{ns}}$ & $91.65 \pm 2.9^{\mathrm{ns}}$ & $90.0 \pm 0.0^{\mathrm{ns}}$ & $86.65 \pm 2.9^{* *}$ & $80.0 \pm 5.0^{* *}$ & $55.0 \pm 5.0^{* *}$ \\
\hline & Oc & $98.3 \pm 2.9$ & $90.0 \pm 0.0^{* *}$ & $90.0 \pm 0.0^{* *}$ & $86.65 \pm 2.9^{* *}$ & $85.0 \pm 0.0^{* *}$ & $60.0 \pm 0.0^{* *}$ & $56.65 \pm 2.9^{* *}$ \\
\hline \multirow{2}{*}{ Seedling length $(\mathrm{cm})$} & $\operatorname{Tm}$ & $10.71 \pm 0.36$ & $11.40 \pm 0.56^{\mathrm{ns}}$ & $11.72 \pm 0.28 \mathrm{~ns}$ & $12.47 \pm 0.12^{*}$ & $11.89 \pm 1.30^{\mathrm{ns}}$ & $9.06 \pm 0.86^{*}$ & $6.96 \pm 0.21^{* *}$ \\
\hline & Oc & $10.71 \pm 0.36$ & $8.14 \pm 0.62^{* *}$ & $6.58 \pm 0.15^{* *}$ & $6.23 \pm 0.54^{* *}$ & $5.85 \pm 0.22^{* *}$ & $5.11 \pm 0.38^{* *}$ & $2.59 \pm 0.23^{* *}$ \\
\hline \multirow{2}{*}{ Dry wt. (mg/seedling) } & $\operatorname{Tm}$ & $7.85 \pm 0.33$ & $7.70 \pm 0.79^{\mathrm{ns}}$ & $7.74 \pm 0.49^{\mathrm{ns}}$ & $8.28 \pm 0.24 \mathrm{~ns}$ & $8.36 \pm 0.48^{\mathrm{ns}}$ & $6.89 \pm 0.54 \mathrm{~ns}$ & $5.99 \pm 0.19^{* *}$ \\
\hline & Oc & $7.85 \pm 0.33$ & $6.20 \pm 0.12^{* *}$ & $6.06 \pm 0.17^{* *}$ & $7.66 \pm 0.19^{\mathrm{ns}}$ & $7.72 \pm 0.15^{\mathrm{ns}}$ & $8.23 \pm 0.11^{\mathrm{ns}}$ & $9.05 \pm 0.28^{* *}$ \\
\hline
\end{tabular}

Note: Tm: T. minuta oil; Oc: cis- $\beta$-ocimene; Values are means \pm Standard deviation; $*$, ** indicate significant

difference from controls at $\mathrm{P}<0.05$ and $\mathrm{P}<0.01$, respectively (in a row), applying Dunnett's test; ns: nonsignificant

The allelopathic effect of direct contact of $C$. occidentalis with the T. minuta oil and cis- $\beta$-ocimene revealed that both treatments reduced overall growth of test seedlings, however, growth inhibition was more significant with cis- $\beta$-ocimene (Table 2). There was reduction in germination percentage of C. occidentalis in dose dependent manner. Seedling lengths of test plant also decreased with maximum inhibition of $75.82 \%$ at $20 \mu \mathrm{g} / \mathrm{cc}$ cis- $\beta$-ocimene treatment. Dry weight changes were not much apparent for most of concentrations, however, at low concentrations, it decreased significantly thereafter increased in dose dependent manner.
Though the exact mechanism for inhibition of germination and growth remains unknown, a number of reports indicate that essential oils and their constituent terpenes inhibit mitotic activity and reduce mitotic index (Romagni et al., 2000; Nishida et al., 2005) which may be the possible reason of suppressed growth.

The inhibitory effect of essential oils and their components on other plants have been reported by many workers (Scrivanti et al., 2003; Singh et al., 2006; de Oliviera et al., 2014; Miranda et al., 2015; de Oliveira et al., 2016; El-Gawad 2016)). The present study provided an instance of allelopathic inhibition of $C$. occidentalis by $T$. minuta oil and cis- $\beta$-ocimene 
for first time. However, the effect of other oil compounds in relation to $c i s-\beta$-ocimene, need to be explored in future.

\section{Conclusions}

The study concludes that $T$. minuta oil and cis- $\beta$ ocimene are strongly allelopathic against $C$. occidentalis. However, the effect of cis- $\beta$-ocimene is more as compared to oil. Since it is the major component, its relative contribution towards overall allelopathy of $T$. minuta oil may be more but its interaction with other components present in oil needs to be further explored in relation to wide variety of weeds.

\section{Acknowledgements}

Grateful thanks are due to Dr. Bikram Singh (CSIRIHBT, Palampur, Himachal Pradesh, India) for identification of chemical composition of $T$. minuta oil.

\section{References}

1. Adams, R.P. "Identification of essential oil components by GC/MS.” Allured Pub. Corp. Carol Stream, USA, (1995).

2. Breme, K, P. Tournayre, X. Fernandez, U.J Meierhenrich, H. Brevards, D. Joulains, and J.L Berdague. "Identification of odor impact compounds of Tagetes minuta L. essential oil: comparison of two GC-olfactometry methods." J Agric Food Chem 57 (2009): 85728580 .

3. Chamorro, E.R, G. Ballerini, A.F Sequeira, G.A Velasco, and M.S Zalazar. "Chemical composition of essential oil from Tagetes minuta L. leaves and flowers." I Argent Chem Soc 96 (2008): 80-86.

4. de Oliveira, C.M, M.D.G Cardoso, A.C.D.S Figueiredo, M.L.M de Carvalho, C.A.S.F.D Miranda, L.R Marques Albuquerque, D. Lee Nelson, M.D Souza Gomes, L.F Silva, J.D Andrade Santiago, et al. "Chemical composition and allelopathic activity of the essential oil from Callistemon viminalis (Myrtaceae) blossoms on lettuce (Lactuca sativa L.) seedlings." Am J Plant Sci 5 (2014): 3551-3557.

5. El Gawad, A.M. "Chemical constituents, antioxidant and potential allelopathic effect of the essential oil from the aerial parts of Cullen plicata." Ind Crop Prod 80 (2016): 36-41.

6. Mc Lafferty F.W. "Registry of mass spectral data." Wiley Publishers, New York, (1989).

7. Meshkatalsadat M.H, J.S Ghomi, S. Moharrmipour, and M. Nasserui. "Chemical characterization of volatile components of
Tagetes minuta L. cultivated in South West of Iran by nano scale injection." Digest J Nanomat Biostruct 5 (2010): 101-106.

8. Miranda, C, M. Cardoso, M. Carvalho, A. Figueiredo, and J. Andrade. "Chemical characterization and allelopathic potential of essential oils from leaves and rhizomes of white ginger." Rev Cienc Agron 46 (2015): 555562.

9. Moghaddam, M, R. Omidbiagi, and F. Sefidkon. "Change in content and chemical composition of Tagetes minuta oil at various harvest times." J Essent Oil Res 19 (2007): 18 20.

10. Mohamed, M.A.H, P.J.C Harris, J. Henderson, and F. Senatore. "Effect of drought stress on the yield and composition of volatile oils of drought-tolerant and non-drought-tolerant clones of Tagetes minuta." Planta Med 68 (2002): 472-474.

11. Nishida, N, S. Tamotsu, N. Nagata, C. Saito, and A. Sakai. "Allelopathic effects of volatile monoterpenoids produced by Salvia leucophylla: Inhibition of cell proliferation and DNA synthesis in the root apical meristem of Brassica campestris seedlings." J Chem Ecol 31 (2005): 1187-1203.

12. de Oliveira, M.S, W.A da Costa, D.S Pereira, J.R.S Bothelho, T.O de Alencar Menezes, E.H de Aquiar Andrade, S.H.M da Silva, A.P da Silva Sousa Filho, and R.N de Carvalho Junior. "Chemical composition and phytotoxic activity of clove (Syzygium aromaticum) essential oil obtained with supercritical $\mathrm{CO}_{2} . "$ J Supercrit Fluids 118 (2016): 185-193.

13. Romagni, J.G, S.N Allen, and F.E Dayan. "Allelopathic effects of volatile cineoles on two weedy plant species." J Chem Ecol 26 (2000): 303-313.

14. Scrivanti, L.R, M.P Zunino, and J.A Zygadlo. "Tagetes minuta and Schinus areira essential oils as allelopathic agents." Biochem Syst Ecol 31(2003): 563-572.

15. Senatore, F, F. Napolitano, M.A.H Mohamed, P.J.C Harris, P.N.S Mnkeni, and J. Henderson. "Antibacterial activity of Tagetes minuta L. (Asteraceae) essential oil with different chemical composition." Flavour Frag J 19 (2004): 574-578.

16. Shahzadi, I, A. Hassan, U.W Khan, and M.M Shah. "Evaluating biological activities of the seed extracts from Tagetes minuta L. found in 
Northern Pakistan.” J Med Plant Res 4 (2010): 2108-2112.

17. Shirazi, M, H. Gholami, G. Kavoosi, V. Rowshan, and A. Tafsiry. "Chemical composition, antioxidant, antimicrobial and cytotoxic activities of Tagetes minuta and Ocimum basilicum essential oils." Food Sci Nutr 2 (2014): 146-155.

18. Singh, H.P, D.R Batish, S. Kaur, K. Arora, and R.K Kohli. "alpha-Pinene inhibits growth and induces oxidative stress in roots." Ann Bot 98 (2006): 1261-1269.

19. Singh, V, B. Singh, and V.K Kaul. "Domestication of wild marigold (Tagetes minuta L.) as a potential economic crop in western Himalaya and north Indian plains." Econ Bot 57 (2003): 535-544.
20. Stein, S.E. "National Institute of Standards and Technology (NIST) Mass spectral data base and Software, Version 3.02." USA, (1990).

21. Syamasundar K.V, and B.R Rajeswara Rao. "Wild marigold (Tagetes minuta L.): cultivation technology and essential oil composition in Natural Essential oils, fragrances and flavours." Edition 1, Aavishkar Publishers, Jaipur, India, (2013) pp 228-248.

\section{Cite this article as:}

Komal Arora, Daizy Batish, Harminder Pal Singh and Ravinder Kumar Kohli. Comparative account of allelopathic potential of essential oil of Tagetes minuta L. and its major component cis- $\beta$-Ocimene. Annals of Plant Sciences 5.9 (2016): 1428-1431.

DOI: http://dx.doi.org/10.21746/aps.2016.09.004

Source of support: Nil.

Conflict of interest: None Declared 